\title{
Supplemental Nutrition Assistance Program participation and racial/ethnic disparities in food and beverage purchases
}

\author{
Anna H Grummon ${ }^{1,2, *}$ and Lindsey Smith Taillie ${ }^{2,3}$ \\ 'Department of Health Behavior, Gillings School of Global Public Health, University of North Carolina at Chapel Hill, \\ 135 Daver Drive, 302 Rosenau Hall, CB\#7440, Chapel Hill, NC 27599, USA: ${ }^{2}$ Carolina Population Center, \\ University of North Carolina at Chapel Hill, Chapel Hill, NC, USA: ${ }^{3}$ Department of Nutrition, Gillings School of \\ Global Public Health, University of North Carolina at Chapel Hill, Chapel Hill, NC, USA
}

Submitted 16 April 2018: Final revision received 22 July 2018: Accepted 3 September 2018: First published online 11 0ctober 2018

\begin{abstract}
Objective: The current study aimed to (i) describe racial/ethnic disparities in household food and beverage purchases among participants and non-participants in the Supplemental Nutrition Assistance Program (SNAP) and (ii) examine longitudinal associations between SNAP participation and purchases by race/ ethnicity.

Design: To describe disparities, we estimated sociodemographic-adjusted mean purchases of seven unhealthy food and beverage groups (e.g. junk food, sugarsweetened beverages) and four nutrients (e.g. sugar, Na) among white, black and Hispanic SNAP-participating and non-participating households. To examine longitudinal associations, we used multivariable linear regression with household fixed effects.

Setting: USA, 2010-2014.

Subjects: Food and beverage purchases among low-income $(\leq 250 \%$ federal poverty line) US households ( $n$ 30 403) participating in the Nielsen Homescan Panel.

Results: Among non-participants, there were significant black-white disparities (i.e. differences favouring white households) in households' adjusted mean purchases of processed meat, sweeteners, sugar-sweetened beverages, energy and $\mathrm{Na}$. These disparities persisted among SNAP participants. In contrast, the only significant Hispanic-white disparity among non-participants was for Na purchases; this disparity was reduced in magnitude and no longer significant among SNAPparticipating households. Additionally, Hispanic households purchased less energy from junk foods than white households, regardless of SNAP status. In longitudinal models accounting for household fixed effects, SNAP participation was associated with increased energy purchased among black households. No other significant longitudinal associations between SNAP and purchase outcomes were observed.

Conclusions: SNAP may not be meeting its potential to improve food and beverage purchases or reduce disparities. Research is needed to identify strategies for ensuring nutritious purchases across all racial/ethnic groups.
\end{abstract}

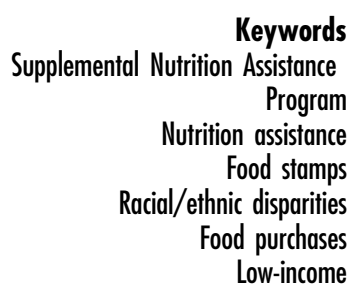

While dietary quality has made small improvements over the last decade, this progress has not benefited all Americans equally: improvements have been smallest for black and Hispanic individuals, and largest for non-Hispanic white individuals ${ }^{(1,2)}$. As a result, disparities in dietary quality have widened over time. Dietary behaviours are important contributors to many of the most pressing chronic diseases in the USA, including obesity, diabetes and $\mathrm{CVD}^{(3-6)}$. In turn, racial/ethnic disparities in dietary outcomes are mirrored by similar disparities in obesity ${ }^{(7)}$, diabetes $^{(8,9)}$ and $\mathrm{CVD}^{(10)}$. Reducing these racial/ethnic disparities remains a national priority ${ }^{(11)}$.

A potential lever for reducing these racial/ethnic disparities is the Supplemental Nutrition Assistance Program (SNAP), a federal nutrition assistance programme that aims to improve its participants' food security and dietary quality. SNAP maintains huge reach among racial/ethnic minorities: each year, approximately $40 \%$ of SNAP 
participants, or about 18 million of SNAP's 45 million participants, are racial/ethnic minorities ${ }^{(12)}$. Thus, if the programme successfully improves dietary quality among these populations, it could serve to alleviate racial/ethnic disparities in dietary behaviours. However, almost no research has examined whether SNAP participation is associated with alleviated or widened racial/ethnic disparities in these outcomes. Further, nearly all studies of SNAP participants' dietary behaviours use cross-sectional data $^{(13)}$. Longitudinal data and models could improve causal inference, but these methods have not yet been used to assess SNAP's impact across a wide range of nutritional behaviours ${ }^{(14-16)}$ or to examine whether programme impact varies across racial/ethnic groups. If SNAP participation benefits some racial/ethnic groups more than others, the programme could serve to either exacerbate or reduce existing racial/ethnic disparities in diet-related behaviours.

To address these gaps in the research, we examined household purchases of key food, beverage and nutrient groups using a national, longitudinal data set of more than 30000 US households followed over time. Our objectives were to describe racial/ethnic disparities in purchases of unhealthy foods, beverages and nutrients among SNAP participants and non-participants, and to examine the longitudinal association between SNAP participation and purchase outcomes among households of differing racial/ ethnic backgrounds.

\section{Methods}

\section{Data and sample}

We used electronic purchase data drawn from the US Homescan Consumer Panel data set. Details on the Homescan Panel have been published previously ${ }^{(17)}$. Briefly, households record their purchases throughout the year using a digital barcode scanner provided by the Nielsen Company. Participants also report on their demographic characteristics via questionnaire, including household composition (household size, presence and ages of children, marital status), age of the household head, educational attainment, household income and the race/ethnicity of the household head.

We used data from the eight quarters during 2010-2014 that contained data on households' SNAP participation (477 225 household-by-quarter observations). We excluded 402 observations with top-coded household size ('nine or more members'), as we could not compute accurate per capita purchases for these households (see the online supplementary material, Supplemental Fig. 1 for a flow diagram of exclusions). Following previous work on SNAP and diet-related behaviours ${ }^{(18)}$, we restricted the sample to low-income households defined as those reporting annual household income $\leq 250 \%$ of the federal poverty level (169912 household-by-quarter observations); thus, all comparisons were between SNAP participants and other low-income households. We excluded observations with missing data on SNAP participation ( $n$ 77 041). Finally, we restricted the sample to households headed by individuals who identified as non-Hispanic White (hereafter 'white'), non-Hispanic Black (hereafter 'black') or Hispanic, and excluded observations in which the household head was in the heterogeneous 'other race' category ( $n$ 3823), leaving an analytic sample of 89048 household-by-quarter observations from 30403 unique households. The average time in the sample was 2.93 quarters.

Households reported their participation in SNAP via survey at eight time points: the beginning of the 2nd quarter of 2010, of the 2nd quarter of 2011, and of both the 2nd and 4th quarters in 2012, 2013 and 2014. We examined purchases made during these eight quarters in which SNAP status was reported (i.e. 2nd quarter of 2010, 2nd quarter of 2011, and 2nd and 4th quarters for 2012-2014). We categorized households as current SNAP participants if they reported currently using SNAP benefits.

Participating households used digital scanners to record the barcode of all packaged foods and beverages they purchased from stores. We linked purchases at the barcode level to detailed nutrition information using Nutrition Facts Panel data ${ }^{(19)}$. To represent long-term, usual behaviours, we aggregated purchases to the quarter level for each household.

Outcomes included purchases of health- and policyrelevant foods and beverages (see online supplementary material, Supplemental Table 1). We focused on purchases of less healthy foods, beverages and nutrients because previous research has found that racial/ethnic disparities have widened over time for consumption of several unhealthy food and nutrient categories (e.g. Na, saturated fat, refined grains) ${ }^{(2)}$ and to inform policy debates focused on whether SNAP should restrict purchases of unhealthy products $^{(20)}$. Specifically, we examined energy from packaged store purchases of: processed meat, desserts and sweet snacks (hereafter 'desserts'), salty snacks, sweeteners and toppings (hereafter 'sweeteners'), candy, junk foods and sugar-sweetened beverages (SSB). To create outcome variables, we followed previous studies ${ }^{(21)}$ by grouping Homescan 'modules' (small sets of similar products, such as 'canned pears,' 'mozzarella cheese' or 'frozen broccoli') into the appropriate category and summing purchases within those categories. For example, the desserts category included all modules for grain- and dairy-based desserts, including frozen baked goods, canned pie fillings, fresh baked goods, frozen desserts and ice cream, baking mixes, cookies and pie shells (Supplemental Table 1). We also assessed total purchases of four nutrients (energy (kcal), saturated fat $(\mathrm{g})$, sugars $(\mathrm{g})$ and $\mathrm{Na}(\mathrm{mg})$ ). For interpretability, we present outcomes in units of kcal, $\mathrm{g}$ or $\mathrm{mg}$ per person per $\mathrm{d}$. We transformed purchases from quarterly totals into units of per person per $\mathrm{d}$ by dividing the total purchases for each quarter by the 
number of days in the quarter and by the number of household members.

\section{Analysis}

To describe racial/ethnic disparities in purchase outcomes by SNAP status, we examined adjusted mean purchases for each racial/ethnic group among SNAP participants and among non-participants, controlling for sociodemographic characteristics (e.g. household composition, education, income), geographic market and total purchases made during the quarter. Models were estimated using pooled ordinary least squares, with se clustered at the household level to account for repeated observations. To compute adjusted mean purchase amounts specific to each raceSNAP group, we included interactions between race/ ethnicity and SNAP participation.

To examine the longitudinal association of SNAP participation with purchase outcomes, we used fixedeffects models adjusting for household sociodemographic characteristics, geographic market and total number of purchases made during the quarter. The key exposure variable was SNAP participation (current participant $v$. non-participant). Fixed-effects models use within-household variation in SNAP participation over time to assess the association of SNAP participation with purchase outcomes, thereby controlling for all time-invariant household characteristics (e.g. stable preferences for particular types of foods). To assess whether the association of SNAP and purchase outcomes varied with race/ethnicity, all models included interactions between race/ethnicity and SNAP participation.

Observations without data on SNAP participation were excluded from analyses. To help account for selection into the analytic sample, we followed previous work ${ }^{(21)}$ by creating time-varying inverse probability weights based on each household's predicted probability of having observed SNAP status during each quarter (see online supplementary material, Supplemental File 1) ${ }^{(22)}$. This process assigns higher weights to complete observations that are more similar to observations with missing SNAP data, thus creating a weighted analytic sample that more closely represents the full sample. Main analyses weight observations using this inverse probability weight. We also conducted sensitivity analyses using unweighted models (Supplemental Table 4 and 5).

\section{Results}

Table 1 reports household characteristics, overall and among households headed by individuals of different racial/ethnic backgrounds. Of the 89048 household-byquarter observations, 15613 or about $17.5 \%$ were current SNAP participants. Participation was highest among black households (26.6\%), followed by Hispanic households $(21.0 \%)$ and white households (16.4\%). Most sample characteristics varied with race/ethnicity.

Table 1 Sample characteristics, overall and among white, black and Hispanic households $†$

\begin{tabular}{|c|c|c|c|c|c|c|c|c|c|}
\hline \multirow[b]{2}{*}{ Characteristic } & \multicolumn{2}{|c|}{ Full sample } & \multicolumn{2}{|c|}{ White } & \multicolumn{2}{|c|}{ Black } & \multicolumn{2}{|c|}{ Hispanic } & \multirow{2}{*}{$\begin{array}{c}P \\
\text { value }\end{array}$} \\
\hline & Mean or \% & SD or $n$ & Mean or \% & SD or $n$ & Mean or \% & SD or $n$ & Mean or \% & SD or $n$ & \\
\hline Current SNAP participant, $\%$ and $n$ & 17.5 & 15613 & $16 \cdot 4$ & 12663 & $26 \cdot 6$ & 2044 & $21 \cdot 0$ & 906 & $<0.001$ \\
\hline \multicolumn{9}{|l|}{ Children } & $<0.001$ \\
\hline Any children, $\%$ and $n$ & $25 \cdot 0$ & 22230 & 23.3 & 17947 & 31.5 & 2428 & $43 \cdot 1$ & 1855 & $<0.001$ \\
\hline Number of children, mean and SD & 0.5 & 1.0 & 0.4 & 0.9 & 0.6 & 1.0 & 0.9 & $1 \cdot 2$ & $<0.001$ \\
\hline $\begin{array}{l}\text { Presence of children under } 2 \text { years, } \\
\% \text { and } n\end{array}$ & 2.5 & 2223 & $2 \cdot 3$ & 1810 & $2 \cdot 6$ & 200 & 4.9 & 213 & $<0.001$ \\
\hline $\begin{array}{l}\text { Presence of children } 2-5 \text { years, } \\
\% \text { and } n\end{array}$ & $6 \cdot 8$ & 6087 & $6 \cdot 3$ & 4886 & $8 \cdot 0$ & 613 & $13 \cdot 7$ & 588 & $<0.001$ \\
\hline $\begin{array}{l}\text { Presence of children } 6-11 \text { years, } \\
\% \text { and } n\end{array}$ & $11 \cdot 4$ & 10188 & $10 \cdot 7$ & 8209 & $13 \cdot 6$ & 1048 & $21 \cdot 6$ & 931 & $<0.001$ \\
\hline $\begin{array}{l}\text { Presence of children } 12-18 \text { years, } \\
\% \text { and } n\end{array}$ & $15 \cdot 7$ & 13950 & $14 \cdot 5$ & 11187 & $21 \cdot 2$ & 1628 & $26 \cdot 4$ & 1135 & $<0.001$ \\
\hline Married, $\%$ and $n$ & $52 \cdot 9$ & 47141 & 53.9 & 41508 & $36 \cdot 2$ & 2788 & $66 \cdot 1$ & 2845 & $<0.001$ \\
\hline $\begin{array}{l}\text { Household head age (years), mean } \\
\text { and SD }\end{array}$ & $59 \cdot 2$ & $13 \cdot 3$ & $59 \cdot 8$ & $13 \cdot 3$ & $56 \cdot 6$ & $12 \cdot 5$ & $53 \cdot 0$ & $13 \cdot 7$ & $<0.001$ \\
\hline \multicolumn{10}{|c|}{ Educational attainment (highest in household), $\%$ and $n$} \\
\hline High school or less & 29.3 & 26129 & $30 \cdot 3$ & 23356 & $21 \cdot 7$ & 1671 & $25 \cdot 6$ & 1102 & $<0.001$ \\
\hline Some college & $35 \cdot 9$ & 31984 & 35.4 & 27255 & 40.5 & 3119 & 37.4 & 1610 & $<0.001$ \\
\hline College graduate & $27 \cdot 7$ & 24681 & $27 \cdot 3$ & 21045 & $30 \cdot 3$ & 2332 & $30 \cdot 3$ & 1304 & $<0.001$ \\
\hline Post-college graduate & 7.0 & 6254 & 7.0 & 5389 & 7.5 & 574 & $6 \cdot 8$ & 291 & 0.25 \\
\hline Income as \% FPL, mean and SD & 1.63 & 0.59 & 1.64 & 0.58 & 1.57 & 0.62 & 1.61 & 0.61 & $<0.001$ \\
\hline Observations, $n$ & - & 89048 & - & 77045 & - & 7696 & - & 4307 & \\
\hline
\end{tabular}

SNAP, Supplemental Nutrition Assistance Program; FPL, federal poverty level.

Source: Authors' own analyses and calculations based in part on data reported by Nielsen through its Homescan Service for the 52 -week periods ending on 31 December 2010; 31 December 2011; 31 December 2012; 31 December 2013; and 31 December 2014. Nielsen data were licensed from the Nielsen Company, 2018.

†Data are from the Nielsen Homescan Consumer Panel, including 30403 US households reporting annual incomes $\leq 250 \%$ of the FPL (89 043 household-byquarter observations).

$\ddagger P$ value from ANOVA (means) or $\chi^{2}$ (proportions) tests comparing white, black and Hispanic households. 
To assess the representativeness of the sample, we qualitatively compared the demographic characteristics of SNAP participants and low-income non-participants in our sample with the same groups in the nationally representative National Household Food Acquisition and Purchase Survey (FoodAPS; see online supplementary material, Supplemental Table 2). The Homescan households were similar in size, income and age to the FoodAPS households, but were less racially/ethnically diverse, had higher educational attainment and were less likely to have children present in the home compared with the FoodAPS sample. The differences between Homescan and FoodAPS participants were similar across SNAP $v$. non-participant households.

In pooled ordinary least-squares models, we observed a number of differences in adjusted mean purchases of foods, beverages and nutrients between white and black households (Fig. 1; see also online supplementary material, Supplemental Table 3). Among non-participants, households headed by a black individual purchased more energy from processed meats, sweeteners and SSB than households headed by a white individual and purchased more total sugars and $\mathrm{Na}$ (all $P<0.05)$. All five of these disparities persisted among SNAP participants (all $P<0.05)$. Further, several disparities between white and black households emerged among SNAP participants that were not present among non-participants. For example, while there were no underlying black-white disparities among non-participants for purchase of junk foods or purchase of total energy, notable disparities emerged among SNAP participants. Compared with white SNAP households, black SNAP households purchased significantly more junk foods (adjusted mean difference $=$ $+153 \cdot 1(95 \%$ CI 31.0, 274.9) kJ/person per d (+36.6 (95\% CI $7 \cdot 4,65.7) \mathrm{kcal} /$ person per d)) and significantly more total energy (adjusted mean difference $=+530 \cdot 9$ (95\% CI $228 \cdot 4,833.5) \mathrm{kJ} /$ person per d (+126.9 (95\% CI 54.6, 199.2) $\mathrm{kcal} /$ person per d)). Additionally, for desserts, salty snacks and candy, non-participant black households showed significant advantages over non-participant white households (i.e. purchased less of these categories, all $P<0.05$ ), but these advantages disappeared among SNAP participants. Figure 1 illuminates the pattern of results: across most outcomes, there are disparities favouring white households over black households (i.e. differences are positive, meaning black households purchase more of the unhealthy category than whites); and these disparities are nearly always larger for SNAP participants (darker bars) compared with non-participants (lighter bars).

The pattern of results differed for Hispanic households (Fig. 2; see also online supplementary material, Supplemental Table 3). For some outcomes, Hispanic nonparticipant households showed advantages over white non-participant households that were not seen among SNAP participants. For example, Hispanic non-participant households had lower purchases of desserts, candy and junk foods than white non-participant households. These

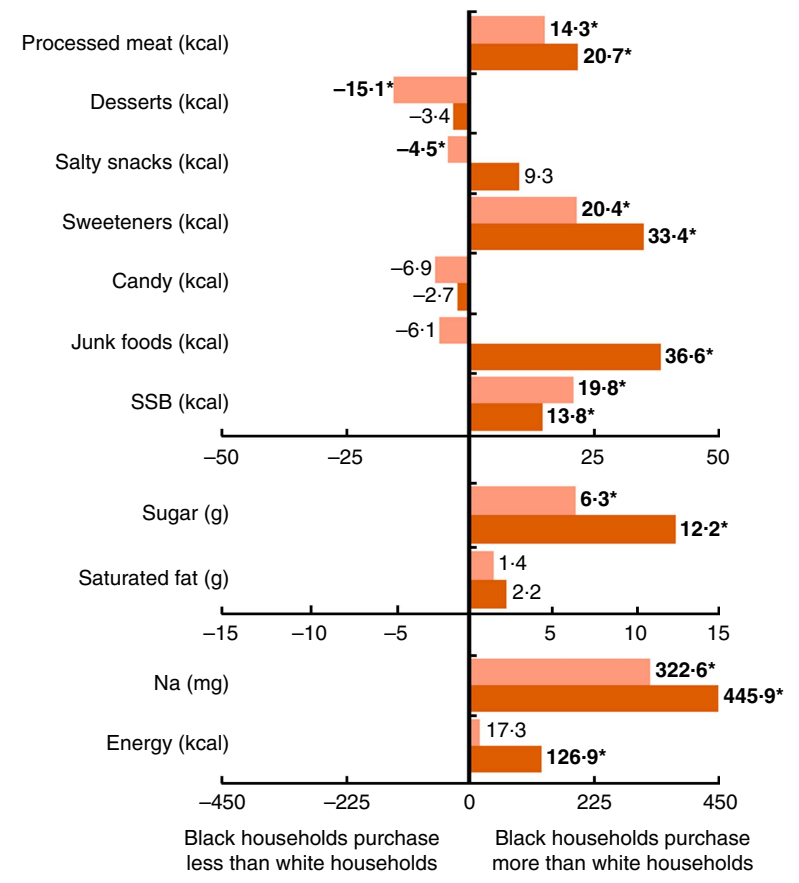

Fig. 1 (colour online) Differences in adjusted mean purchases of black $v$. white households, Supplemental Nutrition Assistant Program (SNAP) participants $(\square)$ and non-participants ( $\square$ ), 2010-2014. Multivariate-adjusted differences, comparing black $v$. white households' per capita per d purchases of foods, beverages and nutrients among SNAP participants and nonparticipants (89043 household-by-quarter observations), controlling for sociodemographic characteristics, geographic market and number of purchases made during the quarter. $A$ positive difference indicates black households had higher adjusted mean purchases compared with white households. Asterisks $\left(^{*}\right)$ and bold font indicate statistically significant adjusted differences $(P<0.05)$. To adjust to $\mathrm{kJ}$, multiply kcal values by 4.184 (SSB, sugar-sweetened beverages). Source: Authors' own analyses and calculations based in part on data reported by Nielsen through its Homescan Service for the 52week periods ending on 31 December 2010; 31 December 2011; 31 December 2012; 31 December 2013; and 31 December 2014. Nielsen data were licensed from the Nielsen Company, 2018

advantages persisted among SNAP participants only for junk food purchases. In contrast, for some outcomes, SNAP participation was associated with new advantages for Hispanic households. For example, Hispanic SNAP households showed an advantage over white SNAP households in purchases of sweeteners (adjusted mean difference (Hispanic households - white households) = -46.9 (95\% CI -80.6, -12.6) kJ/person per d (-11.2 (95\% CI $-19 \cdot 3,-3.0) \mathrm{kcal} /$ person per d)) and grams of total sugar (adjusted mean difference $=-6 \cdot 0$ (95\% CI $-11 \cdot 6$, $-0 \cdot 4) \mathrm{g} /$ person per $\mathrm{d}$ ), despite no underlying advantage in these outcomes observed among non-participants. Further, while Hispanic non-participant households purchased more total $\mathrm{Na}$ than white non-participant households (adjusted mean difference $=+148.7$ (95\% CI 71.5, 225.9) $\mathrm{mg}$ /person per d), among SNAP participants this disparity was reduced in magnitude and no longer statistically significant (adjusted mean difference $=+124 \cdot 2$ 


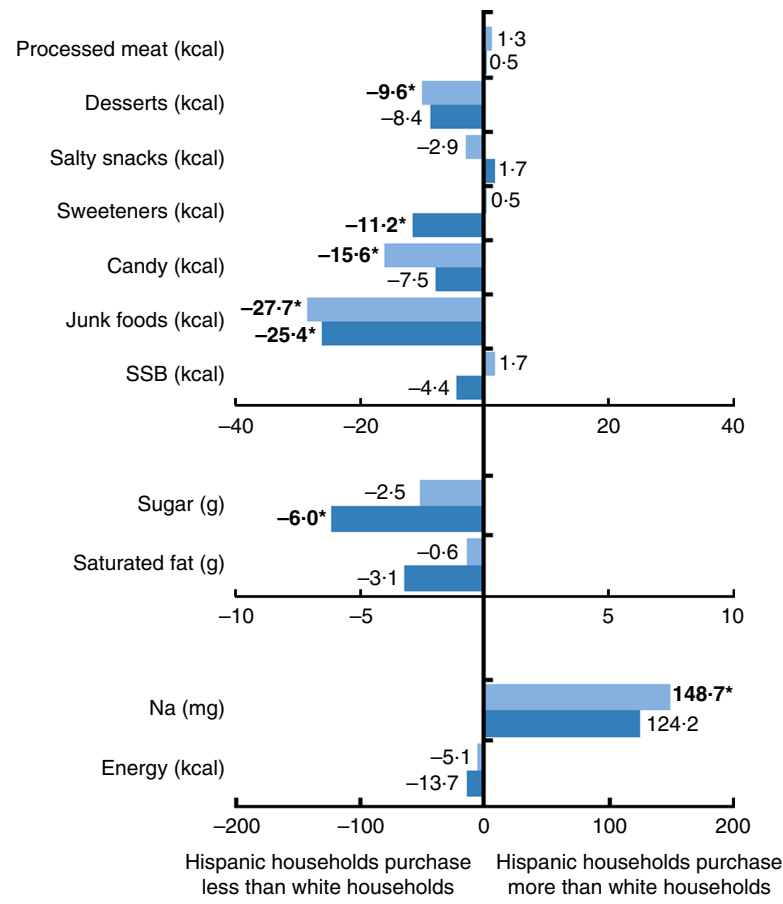

Fig. 2 (colour online) Differences in adjusted mean purchases of Hispanic $v$. white households, Supplemental Nutrition Assistant Program (SNAP) participants $(\square)$ and nonparticipants $(\square), \quad 2010-2014$. Multivariate adjusted differences, comparing Hispanic $v$. white households' per capita per d purchases of foods, beverages and nutrients among SNAP participants and non-participants (89043 household-by-quarter observations), controlling for sociodemographic characteristics, geographic market and number of purchases made during the quarter. A positive difference indicates Hispanic households had higher adjusted mean purchases compared with white households. Asterisks $\left(^{*}\right)$ and bold font indicate statistically significant adjusted differences $(P<0.05)$. To adjust to $\mathrm{kJ}$, multiply kcal values by 4.184 (SSB, sugar-sweetened beverages). Source: Authors' own analyses and calculations based in part on data reported by Nielsen through its Homescan Service for the 52-week periods ending on 31 December 2010; 31 December 2011; 31 December 2012; 31 December 2013; and 31 December 2014. Nielsen data were licensed from the Nielsen Company, 2018

(95\% CI -22.6, 270.9) mg/person per d). There were no significant Hispanic-white disparities in purchases of processed meat, salty snacks, SSB or total energy among either SNAP participants or non-participants.

In longitudinal fixed-effects models, we estimated the association between SNAP participation and purchases once stable household characteristics were controlled for and assessed whether this association differed by race/ ethnicity. There were few statistically significant associations (Table 2). One exception was that SNAP participation was associated with higher purchase of total energy for black households (average difference $=+289 \cdot 1$ (95\% CI $24 \cdot 3,554 \cdot 0) \mathrm{kJ} /$ person per d (+69.1 (95\% CI 5.8, 132.4) $\mathrm{kcal} /$ person per $\mathrm{d})$ ). SNAP participation was also associated with increased energy purchased among white households, but this association did not reach statistical significance (average difference $=+84 \cdot 1$ (95\% CI $-11 \cdot 3$,
179.5) $\mathrm{kJ} /$ person per $\mathrm{d}(+20 \cdot 1(95 \% \mathrm{CI}-2 \cdot 7,42 \cdot 9) \mathrm{kcal} /$ person per d)). In contrast, SNAP participation was associated with decreased energy purchased among Hispanic households, although again the association was not statistically significant at the 0.05 level (average difference $=$ $-286 \cdot 2(95 \% \mathrm{CI}-604 \cdot 6,31 \cdot 8) \mathrm{kJ} /$ person per d $(-68 \cdot 4(95 \%$ CI $-144 \cdot 5,7 \cdot 6) \mathrm{kcal} /$ person per d)).

In sensitivity analyses that did not apply inverse probability weights, we found the same pattern of results for both the ordinary least-square and fixed-effects analyses as in models that applied these weights (see online supplementary material, Supplemental Table 4 and 5).

\section{Discussion}

Using electronic purchase data from a large national sample of US households, the present study found evidence of racial/ethnic disparities in household purchases of foods, beverages and nutrients among both SNAP participants and non-participants. Many of the underlying disparities in purchase outcomes among non-participants mirrored research examining disparities in dietary intake, which generally finds that white individuals have better dietary quality than racial/ethnic minorities. For example, we found that, after adjusting for differing sociodemographic differences, white non-participant households had the lowest mean purchases of SSB. Similarly, using data from the National Health and Nutrition Examination Survey (NHANES), Rehm and colleagues ${ }^{(2)}$ reported that SSB consumption is significantly lower among non-Hispanic white individuals compared with both non-Hispanic black and Mexican-American individuals. We also found that among non-participants, white households purchased less total $\mathrm{Na}$ than black and Hispanic households, mirroring previous findings that black households' purchases have significantly higher Na density than white households ${ }^{(23)}$. Likewise, $\mathrm{Na}$ intake has been stable among white adults during the last decade, but has increased significantly among black and MexicanAmerican adults ${ }^{(2)}$.

SNAP, which serves more than 18 million racial/ethnic minorities annually ${ }^{(12)}$, could be an important lever for reducing these racial/ethnic disparities in dietary behaviours. The present study is one of the first to assess whether the programme is meeting its potential to address disparities. We found evidence that the programme has uneven associations with both purchase outcomes and disparities depending on racial/ethnic group. For example, we observed that the underlying disparities between black and white non-SNAP households' purchases of processed meats, sweeteners, SSB, sugar and $\mathrm{Na}$ all persisted among SNAP households. Additionally, for purchases of junk foods and total energy, there were no underlying blackwhite differences among non-participants, but among SNAP participants we observed significant differences in 
Table 2 Longitudinal associations between participation in the Supplemental Nutrition Assistance Program (SNAP) and household food, beverage and nutrient purchases using fixed-effects models, overall and by race/ethnicity of the household head, 2010-2014†

\begin{tabular}{|c|c|c|c|c|c|c|c|c|c|c|c|c|}
\hline \multirow[b]{4}{*}{ Outcome } & \multicolumn{12}{|c|}{ Average difference, non-participants (referent) $v$. SNAP participants } \\
\hline & \multicolumn{3}{|c|}{ Overall } & \multicolumn{3}{|c|}{ White } & \multicolumn{3}{|c|}{ Black } & \multicolumn{3}{|c|}{ Hispanic } \\
\hline & \multirow[b]{2}{*}{$\begin{array}{l}\text { Avg. } \\
\text { diff. }\end{array}$} & \multicolumn{2}{|c|}{$95 \% \mathrm{Cl}$} & \multirow[b]{2}{*}{$\begin{array}{l}\text { Avg. } \\
\text { diff. }\end{array}$} & \multicolumn{2}{|c|}{$95 \% \mathrm{Cl}$} & \multirow[b]{2}{*}{$\begin{array}{l}\text { Avg. } \\
\text { diff. }\end{array}$} & \multicolumn{2}{|c|}{$95 \% \mathrm{Cl}$} & \multirow[b]{2}{*}{$\begin{array}{l}\text { Avg. } \\
\text { diff. }\end{array}$} & \multicolumn{2}{|c|}{$95 \% \mathrm{Cl}$} \\
\hline & & $\begin{array}{l}\text { Lower } \\
\text { limit }\end{array}$ & $\begin{array}{l}\text { Upper } \\
\text { limit }\end{array}$ & & $\begin{array}{l}\text { Lower } \\
\text { limit }\end{array}$ & $\begin{array}{l}\text { Upper } \\
\text { limit }\end{array}$ & & $\begin{array}{l}\text { Lower } \\
\text { limit }\end{array}$ & $\begin{array}{c}\text { Upper } \\
\text { limit }\end{array}$ & & $\begin{array}{l}\text { Lower } \\
\text { limit }\end{array}$ & $\begin{array}{c}\text { Upper } \\
\text { limit }\end{array}$ \\
\hline \multicolumn{13}{|c|}{ Foods \& beverages (kcal/person per $\mathrm{d}) \S$} \\
\hline Processed meat & 0.4 & -1.5 & $2 \cdot 3$ & 0.8 & -1.4 & 2.9 & -0.2 & $-5 \cdot 0$ & 4.6 & $-3 \cdot 7$ & $-10 \cdot 4$ & 3.0 \\
\hline Desserts & 1.8 & $-2 \cdot 6$ & $6 \cdot 1$ & $2 \cdot 0$ & $-2 \cdot 9$ & 6.9 & 2.5 & $-6 \cdot 7$ & 11.6 & $-3 \cdot 4$ & -19.8 & $13 \cdot 1$ \\
\hline Salty snacks & -2.0 & $-5 \cdot 7$ & 1.7 & -2.5 & $-6 \cdot 7$ & 1.7 & $6 \cdot 6$ & $-1 \cdot 2$ & 14.4 & $-9 \cdot 3$ & $-19 \cdot 7$ & 1.0 \\
\hline Sweeteners & 0.6 & $-2 \cdot 9$ & 4.2 & $1 \cdot 1$ & $-2 \cdot 8$ & $5 \cdot 0$ & -1.5 & $-12 \cdot 3$ & $9 \cdot 2$ & -3.5 & $-13 \cdot 2$ & $6 \cdot 3$ \\
\hline Candy & 0.6 & $-2 \cdot 9$ & 4.2 & 0.2 & $-4 \cdot 3$ & 4.7 & $17 \cdot 8$ & $-19 \cdot 2$ & 54.9 & $-5 \cdot 1$ & $-16 \cdot 9$ & $6 \cdot 7$ \\
\hline Junk food\| & 1.6 & $-3 \cdot 8$ & $7 \cdot 0$ & 0.8 & $-9 \cdot 2$ & $10 \cdot 9$ & 25.4 & $-16 \cdot 2$ & $67 \cdot 0$ & $-21 \cdot 3$ & -50.5 & 7.9 \\
\hline SSB & 2.0 & $-7 \cdot 7$ & 11.7 & 0.8 & $-2 \cdot 5$ & $4 \cdot 1$ & $-4 \cdot 8$ & $-12 \cdot 8$ & $3 \cdot 2$ & 9.0 & -3.0 & $21 \cdot 0$ \\
\hline \multicolumn{13}{|c|}{ Nutrients (per person per d)§ } \\
\hline Energy (kcal) & $20 \cdot 0$ & -0.8 & $40 \cdot 9$ & $20 \cdot 1$ & $-2 \cdot 7$ & $42 \cdot 9$ & $69 \cdot 1^{*}$ & $5 \cdot 8$ & 132.4 & $-68 \cdot 4$ & -144.5 & 7.6 \\
\hline Saturated fat $(\mathrm{g})$ & 0.8 & $-2 \cdot 0$ & 3.7 & 0.5 & $-2 \cdot 7$ & 3.7 & 5.6 & $-1 \cdot 8$ & 12.9 & -2.4 & -6.0 & $1 \cdot 2$ \\
\hline Sugars $(\mathrm{g})$ & 1.2 & -0.6 & 3.1 & 1.3 & -0.6 & 3.3 & $2 \cdot 7$ & -3.3 & 8.7 & $-2 \cdot 8$ & $-9 \cdot 2$ & 3.6 \\
\hline $\mathrm{Na}(\mathrm{mg})$ & $45 \cdot 0$ & $-14 \cdot 0$ & $104 \cdot 0$ & $56 \cdot 0$ & $-8 \cdot 2$ & $120 \cdot 2$ & 32.0 & -136.5 & 200.5 & -104.9 & -344.9 & 135.0 \\
\hline
\end{tabular}

Avg. diff., average differential effect; SSB, sugar-sweetened beverages; FPL, federal poverty level.

Source: Authors' own analyses and calculations based in part on data reported by Nielsen through its Homescan Service for the 52 -week periods ending on 31 December 2010; 31 December 2011; 31 December 2012; 31 December 2013; and 31 December 2014. Nielsen data were licensed from the Nielsen Company, 2018.

${ }^{\star} P<0.05$.

†Data are from the Nielsen Homescan Consumer Panel, including 30403 US households reporting annual incomes $\leq 250 \%$ of the FPL (89 043 household-byquarter observations). All values were determined using fixed-effects models with household as the clustering variable and adjusting for household composition (household size, presence of any children, number of children, presence of children in four age groups (under 2 years, 2-5 years, 6-11 years, 12-18 years)); household structure (married $v$. not)); education (indicators for maximum educational attainment in the household (high school, some college, college graduate, post-college)); income (total household income as \% of the FPL); age of the household head (male or female, whomever was older); geographic market indicators; year; and total number of purchases during the quarter. Models also include an interaction between the race/ethnicity of the household head (white, black, Hispanic) and current participation in SNAP (yes $v$. no). Average differential effects are computed holding other variables at their sample means.

$\ddagger$ Average differential effects are estimates of differences in adjusted mean purchases (per capita per d) of food, beverage and nutrient outcomes between nonparticipants (referent) and participants in SNAP from fixed-effects models, adjusting for covariates. Differences are reported overall (without regard to race/ ethnicity) and for white, black and Hispanic households. A positive average difference indicates that SNAP participants purchase more of the outcome than nonparticipants, while a negative average difference indicates that SNAP participants purchase less of the outcome than non-participants.

$\S$ To adjust to kJ, multiply kcal values by 4184 .

\|Junk food is the sum of purchases of desserts, salty snacks, sweeteners and candy.

these outcomes favouring white households. These results suggest that SNAP may not be meeting its potential to alleviate disparities between white and black households. In contrast, our findings were more mixed for disparities between Hispanic and white households. For example, we observed a significant white-Hispanic disparity in $\mathrm{Na}$ purchases among non-participant households, but this disparity was reduced in magnitude and no longer statistically significant among SNAP participant households. Hispanic SNAP participants also purchased less energy from sweeteners and fewer total grams of sugar than white SNAP participants, an advantage not seen among nonparticipating households. However, while Hispanic nonparticipating households purchased less energy from desserts and from candy than white non-participating households, these advantages were not seen among Hispanic households participating in SNAP.

A number of the observed black-white disparities in food and beverage purchases were large enough to be potentially clinically meaningful. For example, among non-participants, black households purchased $323 \mathrm{mg}$ more Na per person per $d$ than white households, and among SNAP households, this disparity increased to nearly
$450 \mathrm{mg} /$ person per d. Excessive Na consumption increases risk of hypertension and $\mathrm{CVD}^{(24-26)}$, outcomes experienced by black individuals at higher rates than white individuals ${ }^{(27-29)}$. Additionally, purchase of junk foods was more than $146 \mathrm{~kJ}(35 \mathrm{kcal}) /$ person per $\mathrm{d}$ higher among black households participating in SNAP compared with white SNAP households, and purchase of SSB was about $59 \mathrm{~kJ}(14 \mathrm{kcal}) /$ person per d higher among black SNAP households than white SNAP households. Policy makers at the state and federal levels have considered modifying the SNAP benefits package to no longer allow junk foods or SSB to be purchased with SNAP benefits ${ }^{(30-32)}$. While these policies have been debated on ethical and feasibility grounds ${ }^{(20,33-36)}$, our results raise the possibility that if item restrictions are effective at changing behaviour, they could help reduce black-white disparities in purchases of these products.

The present study is among the first to leverage longitudinal fixed-effects models to examine the association between SNAP participation and diet-related behaviours $^{(14-16)}$ and the first to examine whether these associations differ by race/ethnicity. We found that, regardless of racial/ethnic group, there were few statistically 
significant longitudinal associations between SNAP participation and household purchases once fixed household characteristics were accounted for. While results from fixed-effects models cannot be interpreted as causal effects, these findings suggest that SNAP may not be meeting its potential for improving dietary quality. The only statistically significant association we observed in fixed-effects analysis was that, among black households, SNAP participation was associated with an increase in total energy purchased of nearly $293 \mathrm{~kJ}$ ( $70 \mathrm{kcal})$ per household member per $\mathrm{d}$. This result is potentially concerning given the direct relationship between energy intake and obesity ${ }^{(37)}$. On the other hand, increased purchase of energy among black SNAP households could reflect reduced food insecurity, which in turn may be protective against obesity $^{(38,39)}$. Still, our results suggest that any reductions in food security are not translating into improved dietary quality for black SNAP households. This finding is consistent with work by Nguyen and colleagues, who report that SNAP participation is not associated with improvements in dietary quality or weight status among black adults regardless of their food security status ${ }^{(40)}$.

Together, our results suggest that new strategies are needed to improve the nutritional profile of SNAP households' food and beverage purchases and to help SNAP meet its potential for reducing racial/ethnic disparities in dietary outcomes. In addition to item restrictions, mentioned above, other strategies include changes to Supplemental Nutrition Assistance Program-Education (SNAP-Ed). Studies have found that racial/ethnic minorities are less likely to complete SNAP-Ed programmes than white participants ${ }^{(41)}$. Modifying SNAP-Ed delivery modes and reducing other barriers to participation could improve minority participants' access to and participation in SNAP-Ed's nutrition education programming, potentially translating into improvements in their dietary quality. SNAP-Ed content could also be adapted to increase focus on particular topics. For example, research shows that black individuals are less likely to cook their meals at home compared with their white and Hispanic counterparts ${ }^{(42)}$, yet cooking from scratch is often the only way for SNAP households to achieve Thrifty Food Plan nutrition targets while remaining within their SNAP benefits allotment ${ }^{(43,44)}$. SNAP-Ed nutrition programmes might address these disparities by focusing on enhancing cooking skills, particularly among black SNAP participants.

Changes to SNAP policies, including stocking requirements and benefits distribution, might also help the programme better address disparities. For example, SNAP stocking requirements now require stores accepting EBT (electronic balance transfer) payments to stock more varieties of staple foods. Previous research has found that SNAP households located in neighbourhoods with healthier food environments have higher-quality diets ${ }^{(45)}$, suggesting that the new stocking requirements could also help more households achieve nutritious purchases. These changes could provide the greatest benefit to minorities, who have lower access to supermarkets and grocery stores and higher access to convenience stores than white individuals ${ }^{(46,47)}$. Finally, SNAP households tend to overconsume energy shortly after benefits are received each month $^{(48)}$, which can lead to insufficient budget for and foods (especially for healthy products like fruits and vegetables) at the end of the benefit month, resulting in reduced dietary quality ${ }^{(49)}$. To combat this so-called 'SNAP benefits cycle', researchers have suggested distributing SNAP benefits in smaller, more frequent instalments ${ }^{(50)}$. Because the SNAP benefits cycle is more pronounced among households with lower educational attainment ${ }^{(51)}$, efforts to mitigate the cycle could lead to the largest improvements in dietary quality among the most vulnerable households. Whatever strategies are implemented, our results highlight the need to examine whether policies and programmes exert uneven effects across racial/ethnic groups.

\section{Limitations and strengths}

A limitation of the current study is that the data include only packaged food and beverage purchases, and do not reflect purchases of non-packaged items such as loose produce, bulk grains and deli meats. Our choice of outcomes helps mitigate this issue, as the majority of purchases of the food and beverage categories studied here are from packaged products rather than loose/non-packaged items. Another limitation is that Homescan participants may under-report purchases of items that can be easily consumed before recording the barcode (e.g. single beverages, snacks) ${ }^{(52,53)}$, which would mean we underestimate total purchases of these products. While underreporting tends to be higher in households that are larger and have higher income ${ }^{(17,54)}$, we excluded high-income households from analysis and controlled for household size in all analyses. Additionally, while Homescan is a national, population-based sample, our analytic sample differed from a nationally representative sample of lowincome SNAP and non-SNAP households on several characteristics and our results may not generalize to all American households. However, differences between our sample and nationally representative samples did not differ by SNAP status. The Homescan data also do not contain information on level of acculturation among Hispanic households, so we are unable to assess whether the same pattern of results holds for households with differing levels of acculturation. Finally, the study is observational. While all households in the sample were low-income, not all choose to participate in SNAP, and the differences that drive SNAP participation could also be related to food and beverage purchase behaviours. For this reason, our crosssectional results are meant to describe existing differences in purchases across households with different characteristics. Our longitudinal analyses control for time-invariant 
household characteristics to improve causal inference, but there may still be unobserved time-varying confounders that we have not controlled for.

The present study also had several strengths. To our knowledge, it is the first study to examine racial/ethnic disparities in food and beverage purchases among SNAP participants. Other strengths include the use of a large sample with nationwide coverage. Additionally, the electronic purchase data are objectively collected, potentially reducing bias inherent in self-reported dietary intake. Further, households were followed over a long period and thus these data reflect usual behaviours.

\section{Conclusions}

In this nationwide study, we found that there are significant racial/ethnic differences in low-income households' purchases of foods, beverages and nutrients, with many differences favouring white households. For black households, participation in SNAP did not alleviate these disparities, suggesting that SNAP may not be meeting its potential to address black-white disparities in dietary behaviours. Further, SNAP participation was generally not longitudinally associated with reduced purchases of unhealthy products regardless race/ethnic group. Future studies are needed to understand ways to improve the programme to better meet the needs of the diverse population it serves, and to identify strategies for improving purchases and dietary quality across all racial/ ethnic groups.

\section{Supplementary material}

To view supplementary material for this article, please visit https://doi.org/10.1017/S1368980018002598

\section{Acknowledgements}

Acknowledgements: The authors wish to thank Dr Donna Miles for exceptional assistance with data management and Ms Emily Yoon for excellent project management. The authors are grateful to the Robert Wood Johnson Foundation and National Institutes of Health for financial and training support. Financial support: This work was supported by the Robert Wood Johnson Foundation (grant numbers 67506, 68793, 70017 and 71837); and the National Institutes of Health (grant numbers R01DK098072, DK056350, CPC P2C HD050924 and T32 HD007168). The funders had no role in the design, analysis or writing of this article. Conflict of interest: None. Authorship: A.H.G. and L.S.T. designed and conceptualized the study. A.H.G. conducted statistical analyses and drafted the manuscript. L.S.T. oversaw the study.
All authors reviewed and approved the final manuscript. Ethics of buman subject participation: The study was deemed exempt from approval by the University of North Carolina Institutional Review Board.

\section{References}

1. Wang D, Leung C, Li Y et al. (2014) Trends in dietary quality among adults in the United States, 1999 through 2010. JAMA Intern Med 174, 1587-1595.

2. Rehm C, Peñalvo J, Afshin A et al. (2016) Dietary intake among US adults, 1999-2012. JAMA 315, 2542-2553.

3. Mente A, de Koning L, Shannon HS et al. (2009) A systematic review of the evidence supporting a causal link between dietary factors and coronary heart disease. Arch Intern Med 169, 659-669.

4. Ezzati M, Lopez AD, Rodgers A et al. (2002) Selected major risk factors and global and regional burden of disease. Lancet 360, 1347-1360.

5. Danaei G, Ding EL, Mozaffarian D et al. (2009) The preventable causes of death in the United States: comparative risk assessment of dietary, lifestyle, and metabolic risk factors. PLoS Med 6, e1000058.

6. Malik VS, Popkin BM, Bray GA et al. (2010) Sugar-sweetened beverages and risk of metabolic syndrome and type 2 diabetes: a meta-analysis. Diabetes Care 33, 2477-2483.

7. Flegal K, Kruszon-Moran D, Carroll M et al. (2016) Trends in obesity among adults in the United States, 2005 to 2014. JAMA 315, 2284-2291.

8. Cowie CC, Rust KF, Byrd-Holt DD et al. (2010) Prevalence of diabetes and high risk for diabetes using A1C criteria in the US population in 1988-2006. Diabetes Care 33, 562-568.

9. Menke A, Casagrande S, Geiss L et al. (2015) Prevalence of and trends in diabetes among adults in the United States, 1988-2012. JAMA 314, 1021-1029.

10. Centers for Disease Control and Prevention (2011) Prevalence of coronary heart disease: United States, 2006-2010. MMWR Morb Mortal Wkly Rep 60, 1377-1381.

11. US Department of Health and Human Services (2010) The Secretary's Advisory Committee on National Health Promotion and Disease Prevention Objectives for 2020. Phase I Report: Recommendations for the Framework and Format of Healthy People 2020. Washington, DC: US Department of Health and Human Services.

12. US Department of Agriculture (2016) Characteristics of Supplemental Nutrition Assistance Program Households: Fiscal Year 2015. Report no. SNAP-16-CHAR. Alexandria, VA: USDA, Food and Nutrition Service, Office of Policy Support.

13. Andreyeva T, Tripp AS \& Schwartz MB (2015) Dietary quality of Americans by Supplemental Nutrition Assistance Program participation status: a systematic review. Am J Prev Med 49, 594-604.

14. Wilde P \& Nord M (2005) The effect of Food Stamps on food security: a panel data approach. Appl Econ Perspect Policy 27, 425-432.

15. Mabli J \& Ohls J (2015) Supplemental Nutrition Assistance Program participation is associated with an increase in household food security in a national evaluation. $J$ Nutr 145, 344-351.

16. Fernandes MM (2012) Effect of the Supplemental Nutrition Assistance Program (SNAP) on frequency of beverage consumption among youth in the United States. J Acad Nutr Diet 112, 1241-1246.

17. Zhen C, Taylor JL, Muth MK et al. (2009) Understanding differences in self-reported expenditures between 
household scanner data and diary survey data: a comparison of Homescan and Consumer Expenditure Survey. Rev Agric Econ 31, 470-492.

18. Todd JE \& Ver Ploeg M (2014) Caloric beverage intake among adult Supplemental Nutrition Assistance Program participants. Am J Public Health 104, e80-e85.

19. Ng SW \& Popkin BM (2012) Monitoring foods and nutrients sold and consumed in the United States: dynamics and challenges. I Acad Nutr Diet 112, 41-45.e4.

20. Blondin K (2015) Supplemental Nutrition Assistance Program reform: a 21st century policy debate. J Sci Policy Govern September issue, 1-14.

21. Grummon AH \& Taillie LS (2017) Nutritional profile of Supplemental Nutrition Assistance Program household food and beverage purchases. Am J Clin Nutr 105, 14331442 .

22. Seaman SR \& White IR (2013) Review of inverse probability weighting for dealing with missing data. Stat Methods Med Res 22, 278-295.

23. Poti JM, Dunford E \& Popkin BM (2016) Racial/ethnic and income disparities in the sodium content of packaged food purchases by US households in the past 15 years. FASEB J 30, Suppl. 1, 408.8 .

24. Aburto NJ, Ziolkovska A, Hooper L et al. (2013) Effect of lower sodium intake on health: systematic review and metaanalyses. BMJ 346, f1326.

25. Morrison AC \& Ness RB (2011) Sodium intake and cardiovascular disease. Annu Rev Public Health 32, 71-90.

26. Mozaffarian D, Benjamin EJ, Go AS et al. (2016) Heart disease and stroke statistics - 2016 update. Circulation $\mathbf{1 3 3}$ e38-e360.

27. Heidenreich PA, Trogdon JG, Khavjou OA et al. (2011) Forecasting the future of cardiovascular disease in the United States: a policy statement from the American Heart Association. Circulation 123, 933-944.

28. Egan BM, Zhao Y \& Axon R (2010) US trends in prevalence, awareness, treatment, and control of hypertension, 19882008. JAMA 303, 2043-2050.

29. Gillespie CD, Hurvitz KA \& Centers for Disease Control and Prevention (2013) Prevalence of hypertension and controlled hypertension - United States, 2007-2010. MMWR Surveill Summ 62, 144-148.

30. Mistler S (2015) Maine DHHS renews push for ban on buying soda and candy with food stamps. Portland Press Herald, 23 November 2015. https://www.pressherald.com/ 2015/11/23/maine-renews-push-to-prohibit-food-stamprec ipients-from-purchasing-soda-and-candy/ (accessed September 2018).

31. Wagner M (2017) Tennessee lawmaker suggests banning food stamp recipients from buying high-calorie junk, sweets. New York Daily News, 14 January 2017. http:// www.nydailynews.com/news/national/proposed-tenn-lawbans-food-stamp-recipients-buying-junk-article-1.2946475 (accessed September 2018).

32. House Committee on Agriculture (2017) House Agriculture Committee Considers Pros and Cons to Restricting SNAP Purchases. http://agriculture.house.gov/news/documentsingle. aspx? DocumentID=3670 (accessed March 2017).

33. Schwartz MB (2017) Moving beyond the debate over restricting sugary drinks in the Supplemental Nutrition Assistance Program. Am J Prev Med 52, 2S2, S199-S205.

34. Long MW, Leung CW, Cheung LW et al. (2014) Public support for policies to improve the nutritional impact of the Supplemental Nutrition Assistance Program (SNAP). Public Health Nutr 17, 219-224.

35. Cuffey J, Beatty TK \& Harnack L (2015) The potential impact of Supplemental Nutrition Assistance Program (SNAP) restrictions on expenditures: a systematic review. Public Health Nutr 19, 3216-3231.

36. Chrisinger BW (2017) Ethical imperatives against item restriction in the Supplemental Nutrition Assistance Program. Prev Med 100, 56-60.

37. Hall KD, Sacks G, Chandramohan D et al. (2011) Quantification of the effect of energy imbalance on bodyweight. Lancet 378, 826-837.

38. Franklin B, Jones A, Love D et al. (2012) Exploring mediators of food insecurity and obesity: a review of recent literature. J. Community Health 37, 253-264.

39. Dinour LM, Bergen D \& Yeh M-C (2007) The food insecurity-obesity paradox: a review of the literature and the role food stamps may play. J Am Diet Assoc 107, 1952-1961.

40. Nguyen BT, Shuval K, Bertmann F et al. (2015) The Supplemental Nutrition Assistance Program, food insecurity, dietary quality, and obesity among US adults. Am J Public Health 105, 1453-1459.

41. Long V, Cates S, Blitstein J et al. (2013) Supplemental Nutrition Assistance Program Education and Evaluation Study (Wave II). Prepared by Altarum Institute for the US Department of Agriculture, Food, and Nutrition Service. Washington, DC: Altarum Institute.

42. Taillie LS (2018) Who's cooking? Trends in US home food preparation by gender, education, and race/ethnicity from 2003 to 2016. Nutr J 17, 41.

43. Rose D (2007) Food stamps, the Thrifty Food Plan, and meal preparation: the importance of the time dimension for US nutrition policy. J Nutr Educ Behav 39, 226-232.

44. Davis GC \& You W (2011) Not enough money or not enough time to satisfy the Thrifty Food Plan? A cost difference approach for estimating a money-time threshold. Food Policy 36, 101-107.

45. Gustafson A, Lewis S, Perkins S et al. (2013) Neighbourhood and consumer food environment is associated with dietary intake among Supplemental Nutrition Assistance Program (SNAP) participants in Fayette County, Kentucky. Public Health Nutr 16, 1229-1237.

46. Larson NI, Story MT \& Nelson MC (2009) Neighborhood environments: disparities in access to healthy foods in the US. Am J Prev Med 36, 74-81.

47. Walker RE, Keane CR \& Burke JG (2010) Disparities and access to healthy food in the United States: a review of food deserts literature. Health Place 16, 876-884.

48. Shapiro JM (2005) Is there a daily discount rate? Evidence from the food stamp nutrition cycle. J Public Econ 89, 303-325.

49. Whiteman ED, Chrisinger BW \& Hillier A (2018) Diet quality over the monthly Supplemental Nutrition Assistance Program cycle. Am J Prev Med 55, 205-212.

50. National Research Council (2013) Supplemental Nutrition Assistance Program: Examining the Evidence to Define Benefit Adequacy. Washington, DC: National Academies Press.

51. Todd JE (2015) Revisiting the Supplemental Nutrition Assistance Program cycle of food intake: investigating heterogeneity, diet quality, and a large boost in benefit amounts. Appl Econ Perspect Policy 37, 437-458.

52. Einav L, Leibtag E \& Nevo A (2010) Recording discrepancies in Nielsen Homescan data: are they present and do they matter? QME 8, 207-239.

53. Einav L, Leibtag E \& Nevo A (2008) On the Accuracy of Nielsen Homescan Data. Washington, DC: US Department of Agriculture, Economic Research Service.

54. Sweitzer M, Brown D, Karns S et al. (2017) Food-at-Home Expenditures: Comparing Commercial Housebold Scanner Data from IRI and Government Survey Data. Washington, DC: US Department of Agriculture, Economic Research Service. 